\title{
Complementary description of Neanopidium mexicanum (Coleoptera: Tenebrionidae: Anopidiina)
}

\author{
Sergio Aloquio',2 (1) \& Cristiano Lopes-Andrade ${ }^{2}$ (1)
}

\author{
1. Programa de Pós-Graduação em Ecologia, Departamento de Biologia Geral, Universidade Federal de Viçosa, 36570-900 Viçosa, MG, Brazil. \\ (sergio.aloquio@gmail.com) \\ 2. Laboratório de Sistemática e Biologia de Coleoptera, Departamento de Biologia Animal, Universidade Federal de Viçosa, 36570-900 Viçosa, MG, Brazil.
}

Received 28 August 2018

Accepted 13 December 2018

Published 14 January 2019

$10.1590 / 1678-4766 e 2019002$

ABSTRACT. A complementary description for Neanopidium mexicanum Dajoz, 1975, type species of the genus, is provided based on specimens from the type locality Valle Nacional (Oaxaca, Mexico), including description and illustrations of male and female abdominal terminalia, which is provided for the first time to a Neanopidium species.

KEYWORDS. Abdominal terminalia, Diaperinae, Gnathidiini, Mexico.

Anopidiina is a poorly studied pantropical subtribe of Diaperinae comprising 13 genera and about 50 species (Doyen \& LaWrence, 1979; HopP \& Ivie, 2008; SCHAWALleR $\&$ PURCHART, 2012). There were few works on Anopidiina in the last decade, with papers providing new distributional records (Hopp \& IVIE, 2008), description of genus and species (SChawaller \& Purchart, 2012) and solution to nomenclatural problem (IvIE \& SPIESSBERGER, 2017). Neanopidium Dajoz, 1975 is the most diverse genus of Anopidiina, considering extant species, with 13 described species known only from Neotropical areas of Mexico (DAJOZ, 1975, 1977; Doyen \& LAWRENCE, 1979). In the last four decades, there was no taxonomic work on the genus or further distributional data on its species.

A recent loan of unnamed specimens of Diaperinae from the Field Museum of Natural History (FMNH) revealed a small series recognized by us as Neanopidium mexicanum Dajoz, 1975. They are from the type locality, from the same field expedition in which the paratypes were collected, but possibly not examined by Dajoz. The original description is short and lacks information on important structures such as male and female abdominal terminalia. Our aim here is to provide a complementary description of $N$. mexicanum, with emphasis on structures not mentioned in its original description.

\section{MATERIAL AND METHODS}

Specimens were borrowed from the FMNH (Chicago, USA) as unidentified miscellanea of Diaperinae. The dissected specimens (one male, one female and one undetermined due to lack of abdomen) were immersed in hot water for a few minutes, and placed in a $20 \% \mathrm{KOH}$ solution in an $80^{\circ} \mathrm{C}$ water bath for 10-20 minutes to soften and clarifying tissues. They were dissected under a Zeiss Discovery V8 stereomicroscope, and their mouthparts, antennae, metendosternite and abdominal terminalia were removed. The extracted female terminalia were stained in a solution of $0.5 \%$ Chlorazol Black E in $85 \%$ ethyl alcohol for enhancing contrast. Photographs of dissected mandibles were taken under a Zeiss AxioLab light microscope equipped with a Zeiss MRc digital camera; photographs of other dissected parts and habitus were taken under a Zeiss Discovery V20 stereomicroscope equipped with a Zeiss 506 digital camera. Measurements were made under a Zeiss Stemi 2000-C stereomicroscope with a scale ocular. Final images of the habitus were obtained merging photos of different focus using the software Helicon Focus 6 (licensed for the junior author).

Terms for external morphology, including sclerites of terminalia, follow MatTHEws et al. (2010). The following symbols are used for measurements (in $\mathrm{mm}$ ) and ratios: 
EL, elytral length (at midline, from base of scutellar shield to elytral apex); EW, greatest elytral width; GD, greatest depth of body (from elytra to metaventrite); PL, pronotal length along midline; PW, greatest pronotal width; TL, total length (head included); the ratio GD/EW was recorded as an indication of degree of convexity. Measurements provided here are only for the specimens examined by us. For a more complete range of variation in measurements and ratios, see the original description (DAJOz, 1975).

\section{TAXONOMY}

\section{Neanopidium mexicanum Dajoz, 1975}

$$
\text { (Figs } 1 \text { - 12) }
$$

Material examined. Six specimens (one male, one female and four undetermined, FMNH), labeled: "MEX.: OAX.; 32mi S Valle Nacional, 7000' 22.v.1971 S. Peck Ber205, leaf litter".

Complementary description. Males with body (Figs 1-3) strongly convex, somewhat globose, shiny, glabrous except for labrum, legs, antennae and head; dorsum and venter dark reddish brown; mouthparts, legs and antennae dark golden yellow. Head coarsely punctate; punctures closest to each other in occipital region; clypeal suture barely discernible. Mandibles (Figs 4, 5) asymmetrical; outer edge with row of setae; mola and prostheca developed; prostheca membranous; bidentate. Maxillae (Fig. 6) with visible separation between galea and lacinia. Lacinia subcylindrical, with long, stiff setae apically. Galea trapezoidal, apex concave, with long, stiff setae. Maxillary palpi with four palpomeres; apical palpomere lanceolate; apex narrow, with small, rounded sensorial patch; area before apex with patch of small, spatulate sensillae (Fig. 7, arrow). Cardo semicircular. Mentum subquadrate. Labial palpi with three palpomeres; apical palpomere lanceolate, acute apex with rounded sensorial patch. Ligula pentagonal, with acute apex covered with short, stiff setae. Hypopharynx (Fig. 6) membranous, with a triangular sclerite (Fig. 6, arrow). Eyes absent. Antennae (Fig. 8) with 7 antennomeres (club counted as single antennomere, but seems to be fusion of three antennomeres with no visible suture between them, even in slide preparation); stellate sensoria (sensillifers; compound, multi-pronged sensoria sensu LAWRENCE et al., 2011) in inner and outer edges and apex of club; antennal insertions concealed in dorsal view by genal margins.

Pronotum finely punctate, comparatively finer than cephalic punctation; transverse, about $1.5 \mathrm{x}$ as wide as long, widest posteriorly and longest at middle; lateral edges explanate from anterior $1 / 3$ to posterior edge; posterior angles acute; posterior portion not sinuous. Prosternal process large, about as wide as procoxa, subparallel-sided; apex truncate. Elytra about as long as wide in dorsal view, and about $1.8 \mathrm{x}$ as long as pronotum, wider at middle; epipleura with an indentation close to ventrite III, ending abruptly at beginning of last abdominal ventrite; punctation sparse, as coarse as on head. Metendosternite (Fig. 9) with short and narrow stalk, and long slender furcal arms; apex of furcal arms widened. Hind wings absent. Tibiae simple, pubescent, bearing row of spines apically, with two spines slightly longer in inner angle. Tarsal formula 4-4-4.

Abdomen with five ventrites; ventrites I-III connate, ventrites IV and $\mathrm{V}$ free; membrane visible between ventrites III-IV and IV-V; ventrites subparallel-sided until middle of ventrite III, than slightly enlarging to ventrite IV, narrowing to apex. Aedeagus (Fig. 10) with basale about 1.5x as long as apicale; apicale subtriangular, about twice as long as wide, widest at base; basale about $3 \mathrm{x}$ as long as wide, widest at middle, curved ventrally at basal $1 / 3$; penis about as long as basale, lanceolate; ejaculatory duct about $2 \mathrm{x}$ as long as aedeagus. Spicullum gastrale (Fig. 11) horseshoe-shaped, enlarged at base of arms, each arm bearing one long seta basally.

Females similar to males in exposed features. Terminalia (Fig. 12) with bursa copulatrix about as long as gonocoxites together; bursa copulatrix with apical balloonshaped expansion, about as long as bursa; window of bursa and spermatheca absent; accessory gland tubular, about as long as gonocoxites together; ovipositor subquadrate, about as long as wide; paraprocts about $1 / 2$ as long as gonocoxites together, bearing pair of baculi; baculi of gonocoxites oblique to baculi of paraprocts; gonocoxites ventrally divided into four lobes of subequal lengths; each apical lobe with long, slender gonostylus, surrounded by long setae; gonostyli as long as apical lobe of gonocoxites.

Variation. Measurements (in $\mathrm{mm} ; \mathrm{n}=6$ ): $\mathrm{TL}=$ 2.44-2.47 (2.46 \pm 0.01$), \mathrm{PL}=0.78-0.81(0.79 \pm 0.01), \mathrm{PW}$ $=1.25-1.28(1.26 \pm 0.01), \mathrm{EL}=1.34-1.50(1.41 \pm 0.07)$, $\mathrm{EW}=1.47-1.56(1.50 \pm 0.04), \mathrm{GD}=1.09-1.19(1.14 \pm$ 0.04). Ratios: $\mathrm{GD} / \mathrm{EW}=0.74-0.77(0.76 \pm 0.01)$, TL/EW $=1.58-1.68(1.64 \pm 0.04)$.

Comments. Neanopidium mexicanum differs from other species in the genus in being at least $2.4 \mathrm{~mm}$ long, with glabrous pronotum and elytra, elongate antennomeres I-IV, fine and sparse pronotal punctation that is comparatively finer than cephalic punctation, and lateral edges of pronotum not sinuous. The length range of $N$. similis and $N$. pubescens overlaps a little, but in the former the pronotal punctation is coarser than the cephalic punctation, and the lateral edges of pronotum are sinuous posteriorly. Neanopidium pubescens is conspicuously pubescent dorsally. The largest known $N$. lawrencei reachs $2.35 \mathrm{~mm}$, very close to the smallest $N$. mexicanum, which are $2.4 \mathrm{~mm}$ long, but the former is easily discernable by its conspicuous dorsal pubescence. We failed to release specimens from the paper they were glued, even after using a modified Barber's fluid (formula of STÜBEN \& LinSENMAIR, 2009). These specimens are from the same locality as the holotype and paratypes, collected only one day after some of the paratypes. It is important to note that the measurements of the studied series are within the variation mentioned in its original description, but with a comparatively smaller range, given the fewer specimens studied by us. 

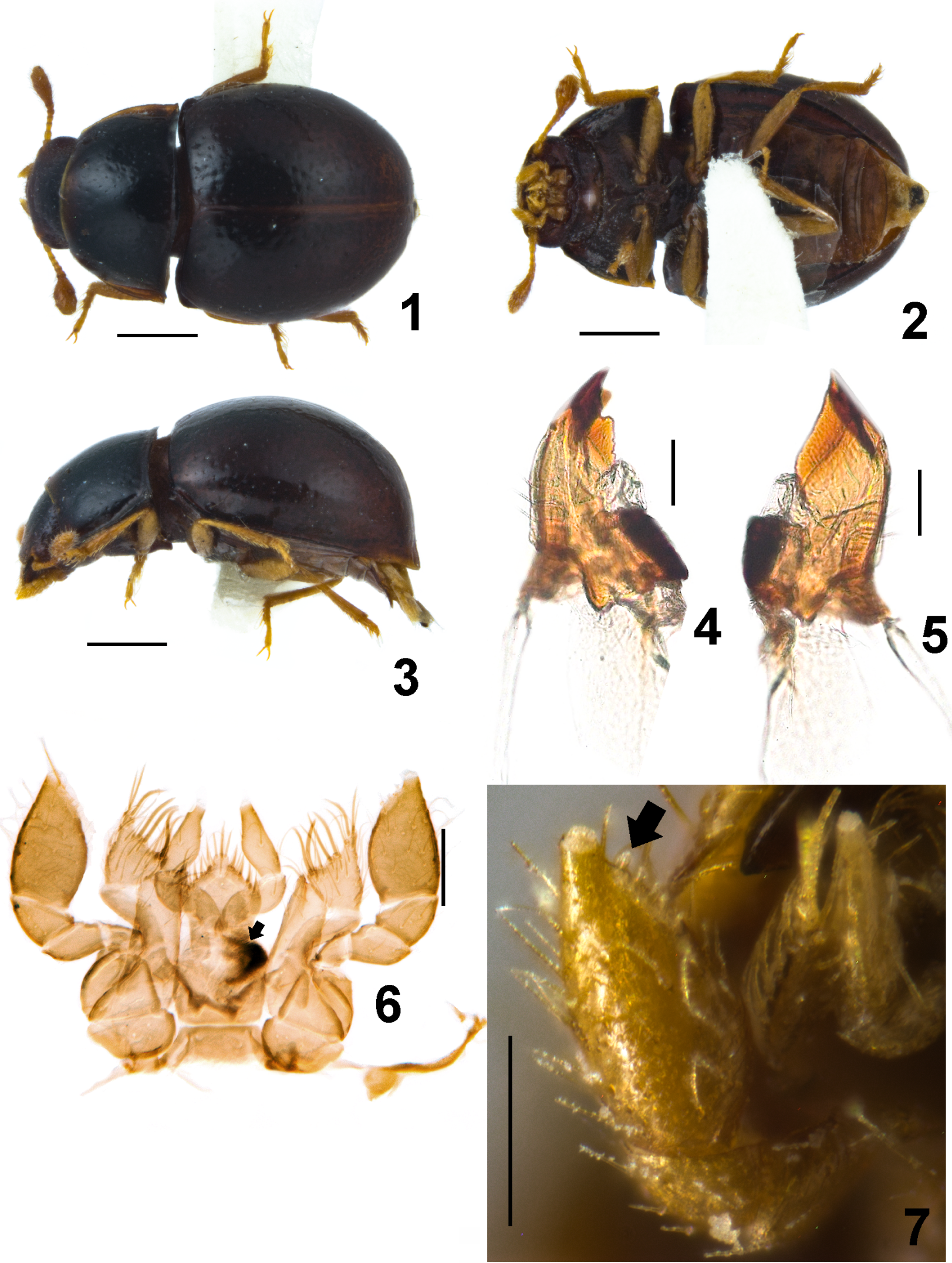

Figs 1-7. Neanopidium mexicanum Dajoz, 1975, habitus: 1, dorsal; 2, ventral; 3, lateral; mandibles: 4, left; 5, right; 6, labrum, maxillae and sclerite of hypopharynx (arrow); 7, detail of apical maxillary palpomere showing spatulate setae (arrow). Scale bars: $0.5 \mathrm{~mm}$ (Figs 1-3), 0.1 mm (Figs 4-7). 


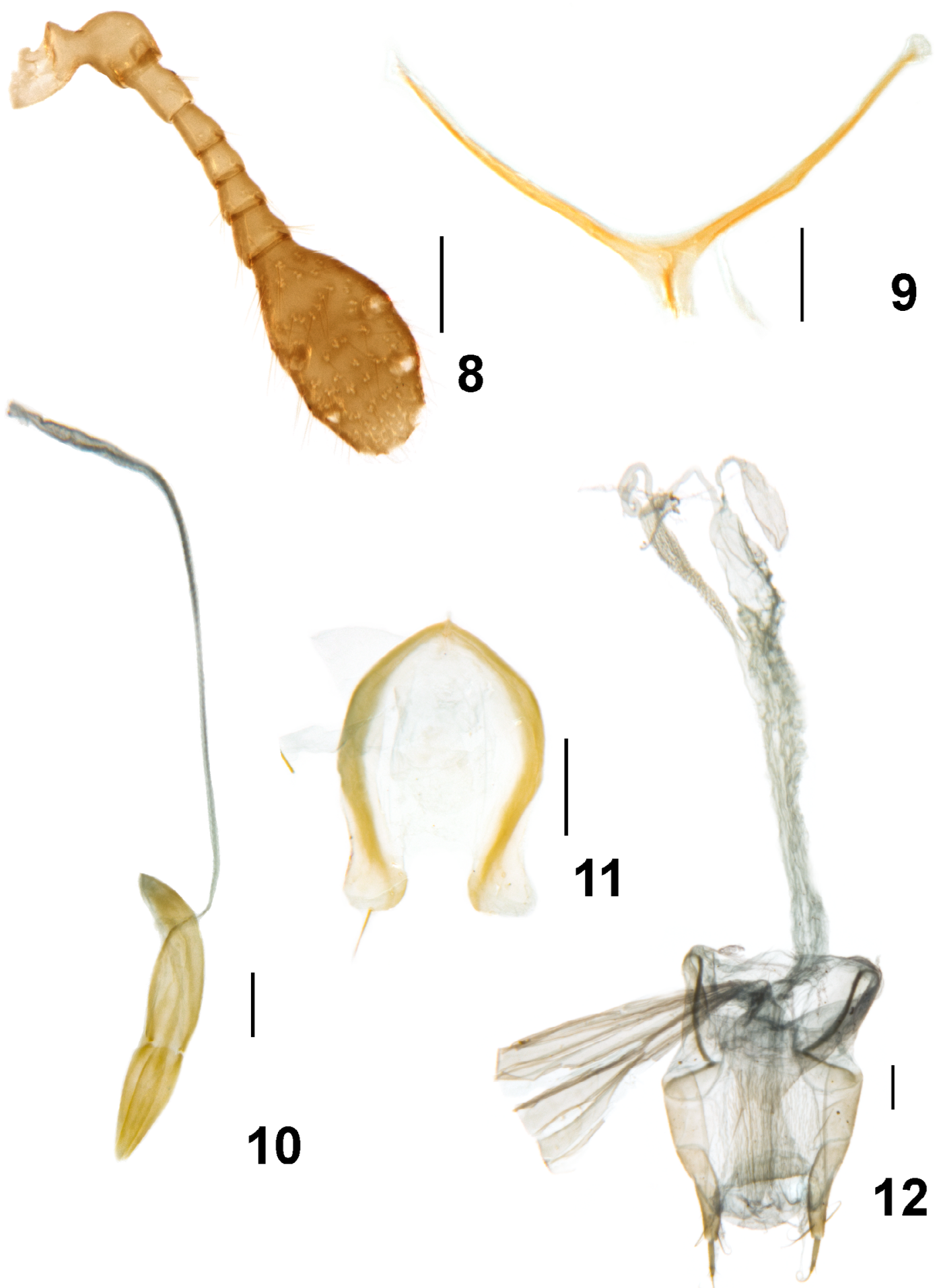

Figs 8-12. Neanopidium mexicanum Dajoz, 1975; 8, antenna; 9, metendosternite; 10, aedeagus in ventral view; 11, spicullum gastrale; 12, female abdominal terminalia. Scale bars: $0.1 \mathrm{~mm}$. 
Acknowledgments. We are grateful to Ms. Crystal Maier (FMNH) who promptly separated and sent the material for study; and to the anonymous referees for corrections and suggestions. Financial support was provided by Fundação de Amparo à Pesquisa do Estado de Minas Gerais (FAPEMIG: Edital 01/2016 - Demanda Universal, APQ-02675-16; Edital FORTIS; Edital 002/2018 - PPM XII, PPM-00314-18; doctoral grant to the senior author), Conselho Nacional de Desenvolvimento Científico e Tecnológico (CNPq: research grant to CLA n ${ }^{\circ} 307116 / 2015-8$ ) and Coordenação de Aperfeiçoamento de Pessoal de Nível Superior - Brasil (CAPES; finance code 001). The senior author thanks Programa de PósGraduação em Ecologia (Universidade Federal de Viçosa, Brazil) for the academic support.

\section{REFERENCES}

DAJOz, R. 1975. Coléoptères Colydiidae et Tenebrionidae anophthalmes nouveaux de la Région Néotropicale. Acta Biológica Paranaense 4(1-2):91-124. doi: 10.5380/abpr.v4i0

DAJoz, R. 1977. Deux nouveaux genres de Colydiidae Anopidiini du Cameroun et de l'ile Maurice (Insects, Coléoptères). Bulletin mensuel de la Société linnéenne de Lyon 46(7):240-245.

Doyen, J. T. \& LaWrence, J. F. 1979. Relationships and higher classification of some Tenebrionidae and Zopheridae (Coleoptera). Systematic Entomology 4:333-377. doi: 10.1111/j.1365-3113.1979.tb00619.x
Hopp, K. J. \& Ivie, M. A. 2008. First report of Tyrtaeus rufus Champion and Tyrtaeus dobsoni Hinton (Tenebrionidae: Diaperinae: Anopidiina) from Florida. The Coleopterists Bulletin 62:427-436. doi: 10.1649/1088.1

IVIE, M. A. \& SPIESSBERGER, E. L. 2017. Clarification of the Correct Spelling of Caecomenimopsis jamaicensis Dajoz (Coleoptera: Tenebrionidae: Diaperinae: Gnathidiini: Anopidiina). The Coleopterists Bulletin 71(1):118-119. doi: 10.1649/0010-065X-71.1.118

Lawrence, J. F.; Ślipiński, A.; Seago, A. E.; Thayer, M. K.; Newton, A. F. \& Marvaldi, A. E. 2011. Phylogeny of the Coleoptera based on morphological characters of adults and larvae. Annales Zoologici 61(1):1-217. doi: 10.3161/000345411X576725

Matthews, E. G.; Lawrence, J. F.; Bouchard, P.; Steiner JR., W. E. \& Ślipiński, A. 2010. 11.14. Tenebrionidae Latreille, 1802. In: LESCHEN, R. A. B.; Beutel, R. G. \& LaWrence, J. F. eds. Handbook of Zoology. A Natural History of the Phyla of the Animal Kingdom. Vol. IV. Arthropoda: Insecta. Part 38. Coleoptera, Beetles. Vol. 2. Systematics (Part 2). Berlin, Walter de Gruyter, p. 574-659.

Schawaller, W. \& Purchart, L. 2012. Nanocaecus hlavaci gen. \& sp. nov. - first record of the tribe Gnathidiini (Coeloptera: Tenebrionidae: Diaperinae) from Socotra Archipelago. Acta Entomologica Musei Nationalis Pragae 52(s2):303-314.

StÜBEn, M. \& LinsenmaIR, K. E. 2009. Advances in insect preparation: bleaching, clearing and relaxing ants (Hymenoptera: Formicidae). Myrmecological News 12:15-21. 